\title{
Diagnostic Tools For The Elevator Business
}

Clemense Ehoff Jr., Kean University, USA

\begin{abstract}
Although much has been written about elevator maintenance from the engineering perspective, little has been written about elevator maintenance from a business perspective. This paper explores some of the business diagnostic tools useful in evaluating elevator maintenance performance and setting elevator performance objectives. These tools may also be applied to other types of maintenance operations.
\end{abstract}

Keywords: Maintenance; Performance; Callbacks; MTBC

\section{INTRODUCTION}

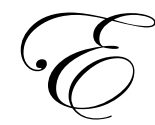

ach year, building owners and managers hire elevator manufacturers and independent service companies to keep their elevators and escalators running smoothly. Elevator maintenance (which includes escalators) generates in excess of $\$ 1$ billion each year. Although much has been written about elevator maintenance from the engineering perspective, little has been written about elevator maintenance from a business perspective. The analysis that follows will examine the elevator maintenance business, and explore some of the business diagnostic tools useful in evaluating elevator maintenance performance and setting elevator maintenance performance objectives.

\section{THE ELEVATOR MAINTENANCE CONTRACT}

Elevator maintenance begins once installation has been completed. Many building owners seem to prefer manufacturer's maintenance, especially while the equipment is under warranty, usually a one-year period. Two categories of elevator maintenance contracts prevail in the U.S. elevator market: full maintenance (FM), and oil and grease (OG). FM contracts generally include preventive maintenance procedures as well as repair and/or replacement of most components. OG contracts generally include minimal inspection; all maintenance procedures, repairs, and replacements are charged to the customer. FM contracts are more prevalent and more lucrative than the OG contracts, so the analysis that follows will focus only on FM contracts.

FM contracts (also commonly referred to as preventive maintenance contracts) typically cover a five-year term with a ninety-day in-writing termination clause. Contractual obligations are explained in considerable detail, and with precise wording. Preventive maintenance is described as a periodic and systematic examination of the elevator, using trained personnel, and including inspection, lubrication, adjustment, and repair or replacement of worn out parts. Elevator work is usually performed during regular working hours. If overtime examinations or repairs are required, customers are typically billed for the overtime bonus hours. Finally, the maintenance contract will exclude liability for vandalism, theft, floods, earthquakes, fire, or misuse; customers are typically charged extra for those types of occurrences. So, by signing the preventive maintenance contract, both parties have agreed to the terms of the contract and share a basic understanding as to what comprises elevator preventive maintenance.

\section{MEASURING PREVENTIVE MAINTENANCE PERFORMANCE}

Elevator manufacturers determine the effectiveness of their FM preventive maintenance in two ways: external and internal. Externally, most elevator service companies restrict performance information to what is explained in the contract. There is usually a paragraph mentioning the keeping of service records, including repairs, callback notes, audits of service personnel, and annual safety inspections. Otis Elevator Company (used as a surrogate for this analysis) follows this practice (1990). Noticeably absent from most contracts is a detailed 
description of (1) the requirements for maintenance quality, and (2) quality standards. Even so, there is at least an implied assumption that the elevator company supervisor, considered an expert, will exercise good professional judgment in performing his job.

Internally, elevators manufacturers determine the effectiveness of their FM preventive maintenance department on the basis of callbacks over a time period. A callback is defined as an event that causes the customer to "call" the elevator maintenance company about a problem, and that event requires the maintenance technician to go "back" to the job site and correct the problem before his next scheduled visit. The statistic frequently used for this purpose is known as mean time between callbacks (MTBC); the greater the mean time the better. This statistic is similar to Accounts Receivable collection days (the fewer collection days the better), frequently used to measure the effectiveness of a firm's collection department, MTBC is expressed by the following equation for a given time period t:

\section{MTBC $=\underline{\text { Number of Units } x t}$ Number of Callbacks}

As an example, assume that during a thirty-day period Company A maintains one hundred elevators and experiences fifty callbacks. MTBC for Company A is 60 days (100 units multiplied by 30 days, divided by 50 callbacks). Preventive maintenance effectiveness is then determined by comparing MTBC to a standard. Preventive maintenance is considered satisfactory if MTBC exceeds the standard, and considered unsatisfactory if MTBC is below the standard. MTBC comparisons have generally been reserved for management purposes only. The reason often cited for restricting this kind of information is that "internal" efficiency measurements of employee productivity are not measurements of elevator operating performance; therefore, these measurements could easily be misinterpreted, causing ill feelings and, in some cases, unnecessary litigation.

What specifically determines satisfactory performance from the customer's viewpoint is not known, although it is reasonable to assume that callbacks and callback response time (the time period from callback to callback resolution) are important factors in the customer's evaluation of satisfactory preventive maintenance, Bell and Zemke (October 1987) have defined customer satisfaction as the point at which experience exactly matches expectation. Of course, finding that "point" is extremely difficult and often different for each customer. Braus (July 1990) points out that expectations are shaped by many factors, including age, sex, race, and income. Thus the difficulty increases as the number of customers increases. So, it is therefore possible for a customer to be dissatisfied with one callback, another customer dissatisfied with what he considers unreasonable callback response time (regardless of the number of callbacks), another customer dissatisfied with paying any overtime premium for after-hours calls, and almost any combination of these outcomes.

Unfortunately there does not seem to be a generally accepted model or performance standard that both manufacturer and customer use to evaluate preventive maintenance. Customers may look for guidance by searching the internet. Windle's "Opening the Door on Elevator Service (2005) and "Three Elevator Performance Measures" by Lorenz (2010) are examples of articles written to assist the building owner (customer) in his evaluation. Elevator consultants are also available to assist building owners and managers in all matters concerning the elevator, including design specification development, purchasing, inspection, evaluation, and expert testimony. Elevator consultants charge a fee for their services, so their services are more likely to be used by the larger and wealthier building owners and building management firms.

So, without a generally accepted standard, maintenance performance measurement has been left to the discretion of whoever is performing the evaluation. There are hundreds of elevator service companies eager to grab customers who are dissatisfied with their existing elevator service company.

\section{A CLOSER LOOK AT MTBC}

The MTBC model has gained acceptance within the elevator industry for measuring preventive maintenance performance for three reasons. First, computing MTBC for a given time period is relatively simple: units divided by callbacks multiplied by the time period. Second, the statistic is easily understood, even by those 
only slightly familiar with the elevator industry. Third, and perhaps most significant, MTBC is primarily a function of preventive maintenance. This point can be shown by examining MTBC from another perspective (Ehoff, 1992):

$M T B C=f(D, A, U, M, L, S)$

This equation defines MTBC as a function of design (D), age of the equipment (A), usage (U), material (M), labor (L), and supervision (S). These factors can be further subdivided into two groups: group 1 (design, age, and usage), and group 2 (material, labor, and supervision). Group 1 consists of factors that cannot be directly altered by the elevator maintenance company. Each elevator design (D) has a unique set of maintenance, lubrication, and replacement parts requirements. Design changes typically involve major modernizations, which occur infrequently, if at all. So, for all practical purposes, the design factor with respect to MTBC is constant. The age factor (A) has a dramatic effect on MTBC. Elevators, like automobiles and other pieces of mechanical equipment, require periodic maintenance, consisting of adjustments and replacement of worn parts. As the equipment ages, the frequency of adjustments and replacement of parts increases. If shown on a graph, maintenance costs would be depicted as an upward sloping line, with costs increasing as each year passes. So, holding all other factors constant, MTBC will likely decrease with the passage of time. Whether the elevator gets heavy or light usage (U) depends upon the type of activities that occur in the particular building. Any change in usage is at the discretion of the building owner or manager, and cannot be altered by the elevator maintenance company. Group 2 items (material, labor, and supervision) are factors that can be directly altered by the elevator maintenance company.

So, to summarize, design, age, and usage factors impose downward pressure in MTBC. The elevator maintenance company, unable to directly change those factors, offsets the effects of the group 1 factors by applying group 1 factors (material, labor, and supervision).

The MTBC model also has value to the elevator company as an analytical tool for setting elevator maintenance performance objectives. In setting a cost objective, the elevator company must take into account that their existing elevators will be a year older, placing downward pressure on MTBC and corresponding upward pressure on maintenance costs. Therefore, it is reasonable to assume that if the average age of maintenance base increases, the following outcomes are likely: 1) MTBC will increase and maintenance costs will rise, 2) MTBC will remain the same and maintenance costs will rise, or 3) MTBC will decrease and maintenance costs will remain the same. What management would like to see is an objective that increases MTBC and correspondingly decreases maintenance costs. Our analysis suggests that a scenario of this sort is rather far fetched and will likely fall short.

\section{CONCLUSION}

Every day, hundreds of elevator manufacturers and independent service companies perform preventive maintenance services to keep our elevators and escalators in good working order. These service companies compete against each other, hoping to acquire a larger share of a market that generates more than $\$ 1$ billion in revenue. The industry standard FM contract covers a five-year period. The contractual language precisely details the duties of each party. Noticeably absent from these contracts is how preventive maintenance is measured; it has surprisingly been left open to conjecture.

MTBC is a statistic used by the elevator companies to measure preventive maintenance performance. The rather simple and easily understood statistic has been analyzed here to show its usefulness in measuring preventive maintenance performance and also in setting performance objectives.

Unfortunately, there does not appear to be a generally accepted model or performance standard that both manufacturer and customer use to evaluate preventive maintenance. MTBC is the likely model for reasons stated above. Determining the appropriate MTBC is another matter. To date, only one MTBC study has been published (Ehoff, 1992). Schindler Elevator Corporation (2002) initiated a customer scorecard that displays MTBC for the last 12 months and other relevant service data. This approach seems promising. At least the customer can perform a two-year comparison, and there does appear to be an attempt by Schindler to be held accountable to a standard, albeit a "soft" one. 
Elevator consultants have begun placing MTBC standards in some of their contracts. Not everyone can afford an elevator consultant, so the effects of these contracts on the entire industry are minimal. Hopefully, more MTBC studies will be published and a MTBC standard can be developed. The elevator service company and the customer will both benefit from the development of a common standard to measure preventive maintenance performance.

\section{AUTHOR INFORMATION}

Dr. Clemense Ehoff Jr., CPA is Assistant Professor of Accounting, Kean University, Union New Jersey. He holds a Ph. D in Business Administration from San Francisco's Golden Gate University. He has more than 30 years professional business experience and has held full-time faculty and adjunct positions at universities predominantly in the Eastern United States. Over the last ten years, Dr. Ehoff has been involved in teaching accounting and tax courses in an online platform. He operates a consulting and tax practice. He has published articles in Elevator World, and other journals.

\section{REFERENCES}

1. Bell, C. R., \& Zemke, R. (October 1987). Service Breakdown: The Road to Recovery. Management Review, 76, 32-35.

2. $\quad$ Braus, P. (July 1990). What is Good Service? American Demographics, 12, 36-39.

3. Ehoff Jr., C. E. (1992) . Removed From Scheduled Maintenance: An Inquiry into the Problems Threatening the Survival of U.S. Elevator Manufacturers (Doctoral Dissertation). Available from ProQuest Dissertations and Theses database. (UMI No. AAT9311161).

4. Lorenz, B. (2010) Three Elevator Performance Measures. Retrieved July 4, 2010 from http://facilitiesnet.com/ security/tip/Three-Elevator-Performance-Measures--20322.

5. Otis Elevator Company. (1990). Extended Coverage Maintenance Contract.

6. Schindler Elevator Corporation (NovembNew Features on Schindler Customer Score Card. Retrieved August 15, 2010 from http://www.us.schindler.com/sec news?news=54847.

7. Windle, L. P. (October 2005). Opening the Door on Elevator Service. Retrieved August 13, 2010 from http://www. Facilitiesnet.com/outsourcing/article/Opening-the-Door-on Elevator-Service-3435. 